\title{
Suicide and suicide attempts in adults: exploring suicide risk 24 months after a psychiatric emergency room visit
}

\author{
Marisa Taron, ${ }^{1,2,3}$ (iD Carla Nunes, ${ }^{4}$ Teresa Maia ${ }^{5}$ \\ ${ }^{1}$ Escola Nacional de Saúde Pública, Universidade Nova de Lisboa, Lisboa, Portugal. ${ }^{2}$ Centro Hospitalar Psiquiátrico de Lisboa, Lisboa, \\ Portugal. ${ }^{3}$ Centro Hospitalar de Lisboa Central, Lisboa, Portugal. ${ }^{4}$ Departamento de Estatística, Escola Nacional de Saúde Pública, \\ Universidade Nova de Lisboa, Lisboa, Portugal. ${ }^{5}$ Departamento de Saúde Mental, Escola Nacional de Saúde Pública, Universidade Nova de \\ Lisboa, Lisboa, Portugal.
}

\begin{abstract}
Objective: Suicide risk (including attempted and completed suicide) should be measured over short periods of time after contacting health services. The objective of this study was to identify the patterns of attempted and completed suicides within 24-months of a psychiatric emergency department visit, as well as to investigate predictive risk factors, including sociodemographic and clinical variables, previous suicidal behavior, and service utilization.

Method: A convenience sample $(n=147)$, recruited at a general hospital's psychiatric emergency room, included patients with suicidal ideation, suicidal plans or previous suicide attempts. These patients were followed for 24 months, focusing on two main outcomes: attempted and completed suicides.

Results: After six months there were no completed suicides and 36 suicide attempts, while after 24 months there were seven completed suicides and 69 suicide attempts. A final logistic regression model for suicide attempts at 24 months identified somatic pathology and the number of previous psychiatric hospitalizations as predictive factors, with a good area under the receiver operating characteristic curve. Conclusions: The findings showed distinct patterns of attempted and completed suicides over time, indicating the importance of a systematic multidisciplinary suicide risk evaluation in psychiatric emergency rooms.
\end{abstract}

Keywords: Repeated suicide attempts; completed suicide; follow-up studies; predictive factors; psychiatric emergency room

\section{Introduction}

The worldwide burden of suicidal behavior and completed suicides, in terms of morbidity, mortality, and health service resources, is overwhelming.

Suicide prevention programs advocate the implementation of suicide prevention measures in emergency rooms (ER), since ER visits are associated with a high prevalence of suicide attempts (SA). In the evolution from suicidal ideation ${ }^{1-3}$ to single or multiple $S A,{ }^{2-9}$ previous SA have been considered the main risk factor for future SA and completed suicides. ${ }^{3-5}$ However, attempts to predict suicidal behavior based on expert risk factor assessment, including machine-learning algorithms, have shown low predictive capacity. ${ }^{10-16}$

The SA rate is up to four times higher than that of completed suicides, and their unpredictability is linked with multiple interactions between risk factors and their dynamics over time. ${ }^{2-4,15,17-19}$ Most completed suicides are preceded by one or two previous $\mathrm{SA},{ }^{20,21}$ with a mean of four. ${ }^{22}$ The repeated SA rate seems to be especially high during the first 6 months after a $S A^{8}$ : this is

Correspondence: Marisa Taron, Av. Padre Cruz, Lisboa, 1600-560, Portugal.

E-mail: marisataron@gmail.com

Submitted Jun 22 2019, accepted Dec 20 2019, Epub May 202020. considered the highest risk period for repeated SA, with rates of up to $9 \% .{ }^{23}$ However, SA rates can reach $60 \%$ within 1-2 years. ${ }^{24}$ Comparatively, the completed suicide rate is approximately $3 \%$ in $1-4$ years of follow-up. ${ }^{25}$

Health service utilization is associated with a statistically significant increase in SA risk, ${ }^{10,22,26-28}$ particularly in the following week ${ }^{29}$ and the following 6 months after a psychiatric hospital discharge.

The main objective of this study was to identify patterns of the two main outcomes, SA and completed suicides, during a 24-month follow-up period, as well as to determine associations between individual characteristics and the outcomes. Data was also collected on the psychiatric ER visits and psychiatric hospitalizations of each participant during the follow-up period.

\section{Method}

\section{Study sample}

Convenience sample recruitment $(n=147)$ occurred at the psychiatric ER of a general hospital for 8 consecutive 
months (September 2015 to April 2016), including psychiatrist referrals for suicide risk. The inclusion criteria were: suicide risk based on suicidal behavior (suicidal ideation or previous SA), age 18-65 years old, and written informed consent to participate in the study. The exclusion criteria were refusal to participate or a clinical condition that prevented the insight and cognitive ability necessary for collaboration.

\section{Study type and period}

This 24-month follow-up study collected data every 6 months after recruitment, although only the first 6 months and the 24-month totals were analyzed. Follow-up was carried out via phone calls every 6 months until the end of the 24-month period. Clinical and administrative patient data was collected from computerized medical records and administrative databases (the national registry of health system users). The two data sources were compared and, in cases of disagreement, the computerized medical records were prioritized.

\section{Definitions}

SA was defined using Portuguese National Suicide Prevention Plan terminology ${ }^{30}$ : "A non-fatal, self-inflicted behavior that necessarily occurred in the presence of suicidal ideation," as opposed to other types of nonsuicidal self-injury behaviors.

\section{Variables}

The following risk factors for SA or completed suicide were selected according to a literature review (Table S1, available as online-only supplementary material):

- Sociodemographic variables, including gender, age, marital status (married or living with a partner vs. other, including single, widowed and divorced) and employment (active vs. inactive).

- Clinical variables, including diagnoses more frequently associated with completed suicides and $\mathrm{SA},{ }^{4,31-33}$ were classified by a psychiatrist into the following categories (not defined by international disease codes): mood disorders (affective or dysthymic), psychotic disorders, alcohol-related disorders, anxiety disorders and other; personality disorders (including the borderline subtype) vs. other (all other personality disorders, including the histrionic subtype); family history (of psychiatric pathologies, SA and completed suicide); and somatic pathology. ${ }^{34}$ Clinical psychopathology, including impulsivity and suicidal ideation, was considered over the last 5 years, either through observation during the interview or through reporting by the patient or relatives. Finally, the lifetime prevalence and type (cutting vs. other) of non-suicidal self-injuries was considered. ${ }^{35-37}$

- Previous SA characteristics: the lifetime prevalence of SA (including the SA that motivated the present emergency visit) and the method used in the most recent SA were classified according to the literature as drug overdose, defenestration, hanging, suffocation, poisoning and phlebotomy, ${ }^{12,23}$ after aggregation into the categories drug overdose and other.

- Prior psychiatric treatment and use of psychiatric services in the past 5 years $^{10}$ included psychiatric consultations, hospital admissions (number of episodes: $0,1,2, \geqslant 3$ ), time since the last episode ( $<1$ year or $\geqslant 1$ year), and visits to the psychiatric $\operatorname{ER}(0,1,2$ or $\geqslant 3$, excluding the present emergency visit).

\section{Statistical analysis}

First, descriptive analyses of the independent variables (sociodemographic, clinical, previous SA and treatment characteristics) and the main outcomes were carried out every 6 months (including total number of SA and completed suicides at 24 months), including measures of central tendency. Second, the chi-square independence test $(p \leqslant 0.05)$ was applied to determine the associations between these risk factors and the two main result indicators (completed suicides and SA) at 24 months. Binary logistic regression was applied to produce a final model (only for repeated SA) after 24 months (enter method, crude and adjusted odds, 95\% confidence interval $[95 \% \mathrm{Cl}] ; \mathrm{p}=0.01-0.02$; and forward method). The receiver operating characteristic curve for this final model was then calculated. SPSS version 22 was used for all analyses.

\section{Ethics statement}

The study protocol was approved by the ethics committee of the investigators' institution and abided by Declaration of Helsinki guidelines. All participants provided written informed consent.

\section{Results}

\section{Sample characterization}

Of the initial sample of 147 patients, only 2 subjects were lost to follow-up. The sociodemographic profile of the sample ( $n=145 ; 2$ missing) included a mean age of $41.9 \pm 11.9$ years and a higher prevalence of women (61.9\%). Clinical features included psychiatric pathology in $94.6 \%$ of the patients, mostly affective or mood disorder $(57.8 \%)$ and personality disorders (59.2\%). Regarding suicidal behavior, $71.4 \%$ of the patients had no history of non-suicidal self-injury, and $95.2 \%$ of the patients had suicidal ideation. In the past 5 years, the patients had a mean of $2.59 \pm 4.51$ emergency visits, and a mean of $1.12 \pm 2.12$ psychiatric hospitalizations. The global sample description is shown in Table S1, available as online-only supplementary material.

\section{Completed suicides, suicide attempts and other results during the 24-month follow-up period}

Data on completed suicides, SA, emergency visits and psychiatric hospitalizations were collected every 6 months (i.e., months 6, 12, 18 and 24). 


\section{Completed suicides}

During the first 6 months there were no completed suicides, and at 12 months there were only two cases. The other five suicides of this study occurred between 18 and 24 months. At the end of the follow-up period, there were a total of seven completed suicides (Table 1, Figure 1). Suicide victims included 5 males and 2 females, aged between 41 and 64 years. The diagnoses were mood disorders (4), psychotic disorder (1), alcohol dependence disorder (1) and one patient with no defined major diagnosis. The suicide methods were drug overdose (3 patients), hanging ( 2 patients), falling down stairs (1 patient) and phlebotomy (1 patient).

\section{Suicide attempts}

During the 24-month follow-up period, a total of 24 patients (15.9\%) attempted suicide: there were 36 episodes at 6 months, 23 episodes between 6 and 12 months,

Table 1 Descriptive analysis of attempted and completed suicides at 24 months $(n=145)$

\begin{tabular}{lcc}
\hline & $\begin{array}{c}6 \text { months } \\
\mathrm{n} \text { (valid \%) }\end{array}$ & $\begin{array}{c}24 \text { months } \\
\mathrm{n} \text { (valid \%) }\end{array}$ \\
\hline Suicides & $0(0.00)$ & $7(4.80)$ \\
Suicide attempts & & \\
Mean (SD); min-max & $0.25(0.79) ; 0-6$ & $0.48(1.82) ; 0-18$ \\
0 & $125(86.2)$ & $122(84.1)$ \\
$\geqslant 1$ & $20(13.8)$ & $24(16.6)$ \\
\hline
\end{tabular}

min-max = minimum-maximum; SD = standard deviation.
5 episodes between 12 and 18 months and 5 episodes between 18 and 24 months, totaling 69 SA (Table 1, Figure 1).

\section{Emergency room visits}

There were a total of 280 emergency visits by 62 patients $(42.8 \%)$, with a mean of $1.93 \pm 7.53$ (range $0-84$ ), distributed as follows: 121 visits during the first 6 months, 24 visits from 6 to 12 months, 15 visits from 12 to 18 months and 19 visits from 18 to 24 months.

\section{Psychiatric hospital admissions}

Psychiatric hospitalizations during follow-up were distributed as follows: 22 admissions between 0 and 6 months, 10 admissions from 6 to 12 months, 7 admissions from 12 to 18 months and 10 admissions from 18 to 24 months, totaling 49 episodes (22 patients, $15.2 \%$ ), with a mean of $0.30 \pm 1.10$ and a range of $0-9$. The independent variables were not correlated with the number of emergency visits or the number of episodes requiring psychiatric hospitalization.

\section{Individual characteristics as risk factors for outcomes}

Individual characteristics as risk factors for completed suicides

There were no completed suicides at 6 months. At 24 months, there were no statistically significant associations

\section{No. of episodes}

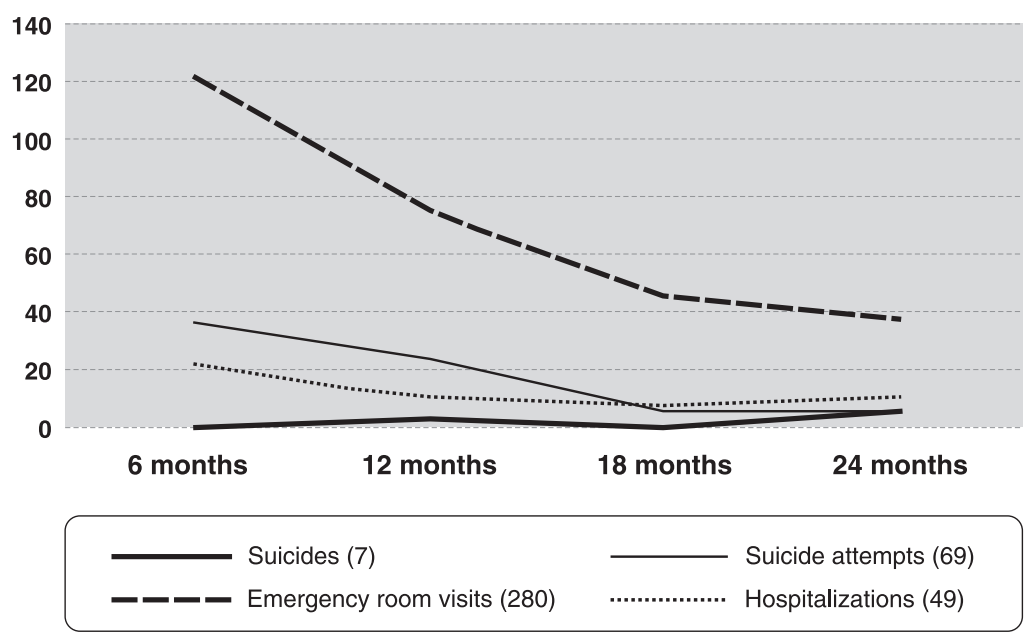

\begin{tabular}{|lccccc|}
\hline Number of episodes & $\mathbf{6}$ months & $\mathbf{1 2}$ months & $\mathbf{1 8}$ months & $\mathbf{2 4}$ months & Total \\
Suicide $(n=7)$ & 0 & 2 & 0 & 5 & 7 \\
Suicide attempts & 36 & 23 & 5 & 5 & 69 \\
Emergency room visits & 121 & 76 & 45 & 38 & 280 \\
Hospitalizations & 22 & 10 & 7 & 10 & 49 \\
\hline
\end{tabular}

Figure 1 Descriptive results: completed suicides, suicide attempts, psychiatric emergency room visits, and psychiatric hospitalizations over 24 months of follow-up. 
(using the chi-square independence test, $p<0.05$ ) between completed suicides and the risk factors (Table 2), although there were only 7 suicides. Due to this small number, the logistic regression analysis for suicides was not carried out.

Individual characteristics as risk factors for SA

The SA rate at 24 months was analyzed using the chisquare independence test. Statistically significant associations were found with the following variables: 1) somatic pathology $(p=0.07) ; 2)$ previous psychiatric consultations $(p=0.04)$; and 3$)$ the existence $(p<0.001)$ and number of previous psychiatric hospitalizations $(0,1$, 2 or $\geqslant 3 ; p<0.006)$. None of the other variables were statistically significant (Table 2). The logistic regression model (crude odds), which focused on SA during the 24-month follow-up period, detected significant associations with only two variables: 1) somatic pathology (OR $2.75 ; 95 \% \mathrm{Cl} 0.87-8.62 ; \mathrm{p}=0.08)$ and 2 ) the number of previous psychiatric hospitalizations $(1,2$ or $\geqslant 3)$, with the reference value being 0 admissions (OR 3.69; $95 \% \mathrm{Cl}$ 1.02-15.96; $p=0.05 ;$ OR 4.03; 95\%Cl 1.02-15.96; $p=$ 0.05 ; OR 5.45; 95\%Cl 1.33-22.29; $p=0.02$, respectively). After adjusting for age and gender, the binary logistic regression showed significant associations between SA during the follow-up period and: 1) the existence of previous psychiatric consultations (OR 4.29; 95\%Cl $1.19-15.41 ; p=0.03$ ) and 2) the number of previous hospitalizations $(1,2$ or $\geqslant 3)$, with the reference value being 0 admissions (OR 4.73; 95\%Cl 1.34-16.75; $\mathrm{p}=$ 0.02; OR 5.32; 95\%Cl 1.39-20.43; p = 0.02; OR 6.14; $95 \% \mathrm{Cl} 1.71-22.07 ; \mathrm{p}=0.005$, respectively). In the final binary logistic regression model (forward method), the variables significantly associated with SA at 24 months were: 1) somatic pathology (OR 2.84; 95\% Cl 1.05-7.69; $p=0.04$ ) and 2) the number of previous psychiatric hospitalizations $(1,2$ or $\geqslant 3)$, with a reference value of 0 admissions (OR 4.04; 95\%Cl 1.17-13.91; $p=0.03$; OR 5.09 ; $95 \% \mathrm{Cl} 1.34-19.36$; $\mathrm{p}=0.02$; OR 7.23 ; $95 \% \mathrm{Cl} 1.96-$ 26.64; $p=0.003$, respectively; Table 3). The final model presented an area under the receiver operating characteristic curve of $0.75(\mathrm{p}=0.05 ; 95 \% \mathrm{Cl} 0.65-0.86)$. This value corresponds to good discriminative power.

\section{Discussion}

The $4.8 \%$ completed suicide rate and the $24.1 \%$ of patients with new SA at the end of the 24-month follow-up period are within the range reported in the international literature. ${ }^{10}$ More SA were observed during the first 6 months of the study period, while most of the completed suicides occurred during the final 6 months, similar to what has been reported in other studies. Age was not significantly associated with SA at 24 months (by chisquare, binary logistic regression, enter method, crude and adjusted to gender and forward method analyses). The only two variables identified as statistically significant independent predictive risk factors for SA at the end of the 24-month follow-up period have already been identified

\begin{tabular}{|c|c|c|c|c|c|c|}
\hline \multirow[b]{2}{*}{ Variables } & \multicolumn{3}{|c|}{ Suicides (n; \%) } & \multicolumn{3}{|c|}{ Suicide attempts (n; \%) } \\
\hline & 0 & 1 & $p$-value & 0 & $\geqslant 1$ & $p$-value \\
\hline \multicolumn{7}{|c|}{ Age (years) } \\
\hline $18-24$ & $13(100.0)$ & $0(0.0)$ & 0.08 & $10(79.6)$ & $3(23.1)$ & 0.51 \\
\hline $25-34$ & $28(100.0)$ & $0(0.0)$ & & $25(89.3)$ & $3(10.7)$ & \\
\hline $35-44$ & 41 (95.3) & $2(4.7)$ & & $37(86.0)$ & $6(14.0)$ & \\
\hline $45-54$ & $33(97.1)$ & $1(2.9)$ & & 30 (88.2) & $4(11.8)$ & \\
\hline $55-65$ & $23(85.2)$ & $4(14.8)$ & & $20(74.1)$ & $7(25.9)$ & \\
\hline \multicolumn{7}{|l|}{ Gender } \\
\hline Male & $49(90.7)$ & $5(9.3)$ & 0.12 & $43(79.6)$ & $11(20.4)$ & 0.47 \\
\hline Female & $89(97.8)$ & $2(2.2)$ & & $79(86.8)$ & $12(13.2)$ & \\
\hline \multicolumn{7}{|c|}{ Somatic pathology } \\
\hline No & $74(94.7)$ & $2(2.6)$ & 0.36 & $68(89.5)$ & $8(10.5)$ & 0.07 \\
\hline Yes & $64(92.8)$ & $5(7.2)$ & & $53(76.8)$ & $16(23.2)$ & \\
\hline \multicolumn{7}{|c|}{ PP consultations } \\
\hline No & $45(93.8)$ & $3(6.3)$ & 0.88 & $45(93.8)$ & 3 (6.3) & 0.04 \\
\hline Yes & 93 (95.9) & $4(4.1)$ & & $76(78.4)$ & $21(21.6)$ & \\
\hline \multicolumn{7}{|c|}{ PP hospitalizations } \\
\hline No & $86(96.6)$ & $3(3.4)$ & 0.53 & $82(92.1)$ & 7 (7.9) & 0.001 \\
\hline Yes & 52 (92.9) & $4(7.1)$ & & $39(69.6)$ & $17(30.4)$ & \\
\hline \multicolumn{7}{|c|}{ Number of PP hospitalizations } \\
\hline 0 & $86(96.6)$ & $3(3.4)$ & 0.74 & $82(92.5)$ & $7(7.9)$ & 0.006 \\
\hline 1 & $20(90.9)$ & $2(9.1)$ & & $16(72.7)$ & $6(27.3)$ & \\
\hline 2 & $15(93.8)$ & $1(6.3)$ & & $11(68.8)$ & $5(31.3)$ & \\
\hline$\geqslant 3$ & $17(94.4)$ & $1(5.6)$ & & $12(66.7)$ & $6(33.3)$ & \\
\hline
\end{tabular}

$\mathrm{PP}=$ previous psychiatric.

Chi-square independence test; $p<0.5$. 
Table 3 Logistic regression of suicide attempts at 24 months $(n=145)^{*}$

\begin{tabular}{|c|c|c|c|}
\hline Variable & Crude odds & Adjusted odds & Forward method \\
\hline \multicolumn{4}{|c|}{ Gender (*Female) } \\
\hline Male & $1.78(0.66-4.80) 0.26$ & - & - \\
\hline \multicolumn{4}{|c|}{ Age $(* 18-24$ years $)$} \\
\hline 25-34 & $0.42(0.06-2.90) 0.38$ & - & - \\
\hline $35-44$ & $0.48(0.08-2.79) 0.42$ & & \\
\hline $45-54$ & $0.39(0.09-2.46) 0.31$ & & \\
\hline $55-65$ & $0.73(0.11-4.82) 0.74$ & & \\
\hline \multicolumn{4}{|c|}{ Somatic pathology (*No) } \\
\hline Yes & $2.75(0.87-8.62) 0.08$ & $2.46(0.90-6.73) 0.13$ & $2.84(1.05-7.69) 0.04$ \\
\hline \multicolumn{4}{|c|}{ PP consultations (*No) } \\
\hline Yes & $2.49(0.61-10.14) 0.20$ & $4.29(1.19-15.41) 0.03$ & \\
\hline \multicolumn{4}{|c|}{$\begin{array}{l}\text { Number of PP hospitalizations } \\
(* 0)\end{array}$} \\
\hline 1 & $3.69(1.02-13.37) 0.05$ & $4.73(1.34-16.75) 0.02$ & $4.04(1.17-13.91) 0.03$ \\
\hline 2 & $4.03(1.02-15.96) 0.05$ & $5.32(1.39-20.43) 0.02$ & 5.09 (1.34-19.36) 0.02 \\
\hline$\geqslant 3$ & $5.45(1.33-22.29) 0.02$ & $6.14(1.71-22.07) 0.005$ & $7.23(1.96-26.64) 0.003$ \\
\hline
\end{tabular}

$\mathrm{PP}=$ previous psychiatric.

* Binary logistic regression (enter method, crude and adjusted to age and gender; forward method; 95\% confidence interval; $\mathrm{p}=0.10-0.20$ ).

in other studies: somatic pathology, ${ }^{15,34}$ and previous psychiatric hospitalizations. ${ }^{11}$ The relevance of the latter might be linked to occasional treatment resistance and possible interactions among risk factors, including sociodemographic and clinical variables that are usually related to SA and repeated SA. ${ }^{4-6}$ The differences between our study and the general literature could be explained by the different methodologies (target population, independent variables, result indicators, study period, etc.).

An important strength of this study is its longitudinal methodology, focusing on SA and completed suicides as its main outcomes, and measuring access to health services (number of emergency and hospital admission episodes), which could be useful for further research. Although this was a longitudinal study, due to the crossreferencing from multiple patient data sources there was no significant reduction in sample size. In fact, the loss of two cases (from 147 to 145 cases) was insignificant to the study sample as a whole. Limitations included the quality of the medical record data, and barriers to computer database access. Furthermore, some of the patient data was self-reported, and there could have been interference from the individual characteristics of the interviewers. Finally, comparison with the literature was limited by a lack of studies with similar methodologies.

In conclusion, the results showed a distinct temporal distribution for completed suicides and SA: there was a higher incidence of SA during the first 6 months, while most completed suicides occurred later, mainly between 18 and 24 months after recruitment. The independent variables associated with SA (somatic pathology and a higher number of previous psychiatric hospitalizations) must be analyzed in an extended longitudinal study to confirm them as predictive factors. Finally, this study represents an investment in suicide risk evaluation in the ER and could lead to the identification of specific patterns of suicidal behavior, as well as to the development of better prevention plans based on the characteristics of suicide risk subpopulations. It also highlights the need for clinicians to be trained in suicide risk assessment, particularly in the ER.

\section{Disclosure}

The authors report no conflicts of interest.

\section{References}

1 Lopez- Castroman JL, Blasco-Fontecilla H, Courtet P, Baca-Garcia $\mathrm{HA}$, Oquendo M. Are we studying the right populations to understand suicide? World Psychiatry. 2015;14:368-9.

2 Dhingra K, Boduszek D, O'Connor RC. Differentiating suicide attempters from suicide ideators using the integrated motivationalvolitional model of suicidal behaviour. J Affect Disord. 2015;186: 211-8.

3 Klonsky ED, May AM, Saffer BY. Suicide, suicide attempts, and suicidal ideation. Annu Rev Clin Psychol. 2016;12:307-30.

4 Choi KH, Wang SM, Yeon B, Suh SY, Oh Y, Lee HK, et al. Risk and protective factors predicting multiple suicide attempts. Psychiatry Res. 2013;210:957-61.

5 Mendez- Bustos P, de Leon-Martinez V, Miret M, Baca-Garcia E, Lopez-Castroman J. Suicide reattempters: a systematic review. Harv Rev Psychiatry. 2013;21:281-95.

6 Lopez-Castroman J, Perez-Rodriguez M, Jaussent I, Alegria AA, Artes-Rodriguez A, Freed $P$, et al. Distinguishing the relevant features of frequent suicide attempters. J Psychiatr Res. 2011;45:619-25.

7 Ando S, Matsumoto T, Kanata S, Hojo A, Yasugi D, Eto N, et al. Oneyear follow-up after admission to an emergency department for drug overdose in Japan. Psychiatry Clin Neurosci. 2013;67:441-50.

8 Beghi M, Rosenbaum JF, Cerri C, Cornaggia CM. Risk factors for fatal and nonfatal repetition of suicide attempts: a literature review. Neuropsychiatr Dis Treat. 2013;9:1725-36.

9 Elisei S, Verdolini N, Anastasi S. Suicidal Attempts among emergency department patients: one year clinical experience. Psychiatr Danub. 2012;24 Suppl 1:S140-2.

10 Monnin J, Thiemard E, Vandel P, Nicolier M, Tio G, Courtet P, et al. Sociodemographic and psychopathological risk factors in repeated suicide attempts: gender differences in a prospective study. J Affect Disord. 2012;136:35-43.

11 Passos IC, Mwangi B, Cao B, Hamilton JE, Wu MJ, Zhang XY, et al. Identifying a clinical signature of suicidology among patients with mood disorders: a pilot study 291 using a machine learning approach. J Affect Disord. 2016;193:109-16. 
12 Runeson $\mathrm{B}$, Tidemalm D, Dahlin M, Lichtenstein $\mathrm{P}$, Långström N. Method of attempted suicide as predictor of subsequent successful suicide: national long term cohort study. BMJ. 2010;341:c3222.

13 Uribe IP, Blasco-Fontecilla H, García-Parés G, Batalla MG, Capdevila ML, Meca AC, et al. Attempted and completed suicide: not what we expected? J Affect Disord. 2013;150:840-6.

14 Zeppegno P, Gramaglia C, Castello LM, Bert F, Gualano MR, Ressino $\mathrm{F}$, et al. Suicide attempts and emergency room psychiatric consultation. BMC Psychiatry. 2015;15:13.

15 Tran T, Luo W, Phung D, Harvey R, Berk M, Kennedy RL, et al. S. Risk stratification using data from electronic medical records better predicts suicide risk than clinician assessments. BMC Psychiatry. 2014;14:76.

16 Ribeiro JD, Franklin JC, Fox KR, Bentley KH, Kleiman EM, Chang $\mathrm{BP}$, et al. Self-injurious thoughts and behaviors and risk factors for future suicide ideation, attempts, and death: a meta-analysis of longitudinal studies. Psychol Med. 2016;46:225-36.

17 Baca-Garcia E, Perez- Rodriguez MM, Oquendo MA, Keyes KM, Hasin DS, Grant BF, et al. Estimating risk for suicide attempt: are we asking the right questions? Passive suicidal ideation as a marker for suicidal behavior. J Affect Disord. 2011;134:327-32.

18 Parra-Uribe I, Blasco-Fontecilla H, Garcia-Parés G, Martínez-Naval L, Valero-Coppin O, et al. Risk of re-attempts and suicide death after a suicide attempt: a survival analysis. BMC Psychiatry. 2017;17:163.

19 Bryan CJ, Rudd MD. The importance of temporal dynamics in the transition from suicidal thought to behaviour. Clin Psychol (New York). 2016;23:21-5.

20 Allen MH, Abar BW, McCormick M, Barnes DH, Haukoos J, Garmel $\mathrm{GM}$, et al. Screening for suicidal ideation and attempts among emergency department medical patients: instrument and results from the psychiatric emergency research collaboration. Suicide Life Threat Behav. 2013;43:313-23.

21 Parra-Uribe I, Blasco-Fontecilla H, García-Parés G, Martínez-Naval L, Valero- Coppin O, Cèbria-Meca A, et al. Risk of re-attempts and suicide death after a suicide attempt: a survival analysis. BMC Psychiatry. 2017;17:163.

22 Kvaran RB, Gunnarsdottir OS, Kristbjornsdottir A, Valdimarsdottir UA, Rafnsson V. Number of visits to the emergency department and risk of suicide: a population-based case-control study. BMC Public Health. 2015;15:227.

23 Bhaskaran J, Wang Y, Roos L, Sareen J, Skakum K, Bolton JM. Method of suicide attempt and reaction to survival as predictors of repeat suicide attempts: a longitudinal analysis. J Clin Psychiatry. 2014;75:e802-8.
24 Daigle MS, Pouliot L, Chagnon F, Greenfield B, Mishara B. Suicide attempts: prevention of repetition. Can J Psychiatry. 2011;56:621-9.

25 Owens D, Horrocks J, House A. Fatal and non-fatal repetition of selfharm. Systematic review. Br J Psychiatry. 2002;181:193-9.

26 Olfson M. Suicide risk after psychiatric hospital discharge. JAMA Psychiatry. 2017;74:669-70.

27 Kapur N, Steeg S, Turnbull P, Webb R, Bergen H, Hawton K, et al. Hospital management of suicidal behavior and subsequent mortality: a prospective cohort study. Lancet Psychiatry. 2015;2:809-16.

28 Hjorthøj C, Madsen T, Agerbo E, Nordentoft M. Risk of suicide according to level of psychiatric treatment: a nationwide nested case-control study. Soc Psychiatry Psychiatr Epidemiol. 2014;49: 1357-65.

29 Bickley H, Hunt IM, Windfuhr K, Shaw J, Appleby L, Kapur N. Suicide within two weeks of discharge from psychiatric inpatient care: a casecontrol study. Psychiatr Serv. 2013;64:653-9.

30 Portugal, Ministério da Saúde. Programa Nacional Saúde Mental. Plano Nacional de Prevenção do Suicídio 2013-2017. 2014 [cited 2010 Mar 9]. www.dgs.pt/documentos-e-publicacoes/plano-nacionalde-prevencao-do-suicido-20132017-pdf.aspx

31 Pompili M, Serafini G, Innamorati M, Dominici G, Ferracuti S, Kotzalidis GD, et al. Suicidal behavior and alcohol abuse. Int J Environ Res Public Health. 2010;7:1392-431.

32 Pompili M, Innamorati M, Lester D, Serafini G, Erbuto D, Battuello M, et al. Suicide attempts in acute psychiatric referrals with substance use disorders. Riv Psichiatr. 2012;47:313-8.

33 Narishige R, Kawashima Y, Otaka Y, Saito T, Okubo Y. Gender differences in suicide attempters: a retrospective study of precipitating factors for suicide attempts at a critical emergency unit in Japan. BMC Psychiatry. 2014;14:144.

34 Bertolote JM, Mello-Santos C, Botega NJ. [Detecting suicide risk at psychiatric emergency services]. Braz J Psychiatry. 2010;32 Suppl 2: S87-95.

35 Mergl R, Koburger N, Heinrichs K, Székely A, Tóth MD, Coyne J, et al. What are reasons for the large gender differences in the lethality of suicidal acts? An epidemiological analysis in four European countries. PLoS One. 2015;10:e0129062.

36 Hawton K, Bergen H, Cooper J, Turnbull P, Waters K, Ness J, et al. Suicide following self-harm: findings from the multicentre study of self-harm in England, 2000-2012. J Affect Disord. 2015;175: 147-51.

37 Pompili M, Goracci A, Giordano G, Erbuto D, Girardi P, Klonsky ED, et al. Relationship of non-suicidal self-injury and suicide attempt: a psychopathological Perspective. J Psychopathol. 2015;21:348-53. 